\title{
Corporate taxes, growth and welfare in a Schumpeterian economy
}

\author{
Pietro F. Peretto* \\ Department of Economics, Duke University, Durham, NC 27708, USA \\ Received 25 March 2005; final version received 23 November 2006 \\ Available online 25 January 2007
}

\begin{abstract}
I take a new look at the long-run implications of taxation through the lens of modern Schumpeterian growth theory. I focus on the latest vintage of models that sterilize the scale effect through a process of product proliferation that fragments the aggregate market into submarkets whose size does not increase with the size of the workforce. I show that the following interventions raise welfare: (a) granting full expensibility of R\&D to incorporated firms; (b) eliminating the corporate income tax and/or the capital gains tax; (c) reducing taxes on labor and/or consumption. What makes these results remarkable is that in all three cases the endogenous increase in the tax on dividends necessary to balance the budget has a positive effect on growth. A general implication of my analysis is that corporate taxation plays a special role in Schumpeterian economies and provides novel insights on how to design welfare-enhancing tax reforms.

(C) 2007 Elsevier Inc. All rights reserved.
\end{abstract}

JEL classification: E10; L16; O31; O40

Keywords: Endogenous growth; Market structure; Dividends; Corporate Taxation

\section{Introduction}

The Job Growth and Taxpayer Relief Reconciliation Act of 2003 (JGTRRA) reduced substantially the tax rates on individual dividend income and on capital gains from sales of corporate shares. Supporters of this legislation argue that it will reduce the corporate cost of capital and thus raise investment, growth and employment. Critics tend to focus on the Act's distributional implications and on the large budget deficits that it will generate. Regardless of the side that one takes in this debate, the JGTRRA has revived economists' interest in the macroeconomic implications of changes in taxation of the earnings from corporate activity. Much of the current work

\footnotetext{
* Fax: +1 9196848974 .

E-mail address: peretto@econ.duke.edu.
} 
investigates the possible short-run stimulus to aggregate demand and the long-run implications for saving and growth within the framework of the neoclassical model of capital accumulation.

In this paper, I take a new look at the long-run implications of fiscal policy through the lens of modern Schumpeterian growth theory. The novel elements introduced by the theory-imperfect competition, accumulation of intangibles, economies of scale, the distinction between growth of existing product lines and creation of new product lines - shed new light on the workings of taxation.

I focus on the latest vintage of Schumpeterian models that sterilize the scale effect of the size of the aggregate market on firms' incentives to do R\&D through a process of product proliferation that fragments the aggregate market into submarkets whose size does not increase with the size of the workforce. As is well known, the sterilization of the scale effect through this mechanism allows one to introduce population growth and elastic labor supply without getting counterfactually large changes in the economy's growth rate. More importantly, it implies that fundamentals and policy variables that work through the size of the aggregate market do not affect steady-state growth; they only have transitory effects that, nevertheless, are important determinants of welfare. In contrast, fundamentals and policy variables that reallocate resources between productivity growth and product proliferation do have long-run growth effects. ${ }^{1}$

An important innovation that characterizes this paper is that I follow Peretto and Connolly [17] and introduce a fixed operating cost per product line (firm) to draw a sharp distinction between the horizontal (variety) and vertical (quality-productivity) dimensions of technology space. Specifically, steady-state growth driven by product proliferation cannot occur independently of population growth because fixed costs imply that at any point in time the number of products is constrained by the size of the workforce. In the vertical dimension, in contrast, steady-state growth is feasible because progress along the quality/productivity ladder does not require the replication of fixed costs. This property assigns a novel and important role to taxes that apply to corporate profits (e.g., taxes on corporate income and on distributed dividends). The reason is that they affect differently the returns to investing in the growth of existing product lines and in the development of new product lines, and thus reallocate resources across activities that have different growth opportunity. The model that I use is very tractable and allows me to study analytically transition dynamics and welfare in response to changes in tax rates.

My main results concern equilibrium dynamics under the assumption that the government has no access to lump-sum taxes or public debt, holds constant the fraction of GDP allocated to (unproductive) public expenditures, and balances the budget at all times by endogenously setting the tax rate on the dividend income earned by households. I show that

- Granting full expensibility of R\&D to incorporated firms (equivalently, subsidizing R\&D at the same rate as the corporate income tax) is welfare improving.

- Eliminating the corporate income tax and/or the capital gains tax is welfare improving.

- Reducing taxes on labor and/or consumption is welfare improving.

\footnotetext{
${ }^{1}$ As is well known, first-generation endogenous growth models feature a positive relation between aggregate market size and growth that results in a positive relation between the scale of aggregate economic activity and the growth rate of income per capita. This is a problem for the theory because there is no evidence that larger economies grow faster (see, e.g., $[4,9,10,6])$. Several contributions proposed solutions based on product proliferation: Peretto [14,15], Dinopoulos and Thompson [5], Young [20], and Howitt [8]. See Jones [11], Aghion and Howitt [1,2], Peretto and Smulders [18], and Laincz and Peretto [13] for reviews of the various approaches and of the empirical evidence. Zeng and Zhang [21] and Peretto [16] study the implications of the elimination of the scale effect for tax policy but consider steady states only and ignore welfare.
} 
Recall that in all three cases the government makes up the revenue shortfall by raising the tax rate on dividend income. This is what makes these results remarkable. In all cases welfare rises unambiguously because the endogenous increase in the tax on dividends necessary to balance the budget has a positive effect on growth. The reason is that the dividend income tax reallocates resources from product proliferation to productivity growth.

The analysis assigns the above policies to two classes: (a) policies that do not change the required revenue flow that taxation of the firms' earnings must deliver but change the relative importance of specific taxes in generating that revenue (i.e., taxes on corporate income, on personal dividend income and on capital gains); (b) policies that change the revenue flow that these taxes have to generate. Granting full expensibility of corporate R\&D and/or eliminating taxes on corporate income and capital gains eliminate the distortions of the firms' investment decisions. Financing these changes with the tax on dividends implies that the policy does not require adjustments in, e.g., taxes on labor income. In other words, policies of class (a) concern only taxation of corporate earnings and, in practice, amount to resetting the relative importance of each tax. The analysis shows that repealing taxation of corporate earnings and capital gains, replacing it with taxation of distributed dividends, raises welfare. (Eliminating the corporate income tax eliminates the distortionary effect of partial expensibility of R\&D so that, in practice, the first policy becomes redundant.) The intuition is that taxes that have adverse growth effects because they distort the production/investment decisions of firms are replaced by a tax that has the positive growth effect discussed above.

Policies of class (b) change the required flow of revenue that taxation of dividends must generate and thereby increase the resulting distortion in favor of quality growth. It is somewhat surprising to learn that reducing taxes on labor income and increasing taxes on dividends raises welfare. The intuition, however, is straightforward. Reducing taxes that affect households (i.e., taxes on labor income and consumption) reduces distortions of labor supply, consumption and saving. This increases welfare through level effects, that is, changes in steady-state consumption and leisure. As stated above, using the dividend tax to make up the revenue shortfall has a further positive growth effect. Thus, these policies raise welfare because of favorable level and growth effects.

Before moving on to the analysis, it is useful to step back and assess my results in general terms. A natural question to ask is: what is the "deep" reason why one should expect the dividend tax to raise welfare? Is there an externality hiding behind the quality-variety trade-off that the market fails to internalize? The answer is: yes, there is. Entrants fail to take into account that by expanding product variety they dilute the incentives of inframarginal firms to invest in the growth of their product lines. The tax on dividends corrects the situation by penalizing entry—relative to incumbent growth - and thereby weakening the associated dilution effect.

A related question is whether the revenue neutrality of my tax experiments is a necessary component of the story. That is, one might wonder whether, in light of the market failure highlighted above, it is possible to obtain growth and welfare increases by raising the dividend income tax and allocating the revenues to unproductive uses. The answer is: yes, it is. The dividend tax hike can raise welfare because it speeds up quality growth by reducing product variety and thereby concentrating investment resources on a larger mass of products per capita. If social returns to variety are low the welfare effect of this transition is positive. If social returns to variety are high, in contrast, the acceleration of quality growth does not compensate the loss of specialization due to the variety slowdown and welfare falls.

This is where the revenue-neutral tax experiments differ crucially from the case of wasted revenues, and why I think they yield the more interesting results: allocating the dividend tax revenues to lowering another distortionary tax (say on labor), and thereby expanding market size, 
ensures that product variety rises. Differently from levying dividend taxes and throwing revenues in the ocean - a policy that I am not willing to recommend — this policy does not entail a movement along the quality-variety trade-off but an improvement of the trade-off itself. Thus, while I think that a strong message of my model is that the dividend income tax yields growth and (potentially) welfare benefits independent of the use of the revenues it raises, I do not emphasize it as its most important implication. Rather, the main message of my Schumpeterian analysis is that there are aspects of corporate taxation that provide novel opportunities-so far largely unexplored by the literature-for designing welfare-enhancing (second-best) reforms of the overall structure of taxation.

The paper is organized as follows. Section 2 sets up the model. Section 3 characterizes equilibrium dynamics and establishes the main comparative statics properties. Section 4 studies revenueneutral changes in taxation and establishes the main policy-oriented results. Section 5 discusses robustness to plausible modifications of the environment and proposes an interpretation of the key mechanism. Section 6 concludes. The Appendix discusses in some additional detail the robustness of the results by sketching minor modifications of the model that yield the same qualitative results as the version discussed in the main body of the paper.

\section{The model}

The economy is closed. To keep things as simple as possible, I abstract from physical capital and public debt. In particular, I construct a model where the household's portfolio contains only securities (shares) issued by firms. These are backed up by intangible productive assets accumulated through $\mathrm{R} \& \mathrm{D}$. Thus, in this environment the dividend income earned by households stems from vertical (quality) ${ }^{2}$ and horizontal (variety) product differentiation. ${ }^{3}$ Introducing physical capital in this structure is feasible (see, e.g., [1]) but complicates the analysis without changing the basic results.

\subsection{Final producers}

A competitive representative firm produces a final good $Y$ that can be consumed, used to produce intermediate goods, invested in R\&D that rises the quality of existing intermediate goods, or invested in the creation of new intermediate goods. The price of this final good is the numeraire, $P_{Y} \equiv 1$. The production technology is

$$
Y=\int_{0}^{N} X_{i}^{\theta}\left(Z_{i}^{\alpha} Z^{1-\alpha} L_{i}\right)^{1-\theta} d i, \quad 0<\theta, \alpha<1
$$

\footnotetext{
${ }^{2}$ Cost reduction and quality improvements are isomorphic in this environment where customers care about the services they derive from the products that they purchase. Hence, the vertical dimension of innovation can be either quality (product innovation) or productivity (process innovation) without changing the paper's insight.

${ }^{3}$ It is useful to be precise here. There is no capital in the usual neoclassical sense of a homogenous, durable, intermediate good accumulated through foregone consumption. Instead, there are differentiated, non-durable, intermediate goods produced through foregone consumption. One can think of these goods as capital, albeit with $100 \%$ instantaneous depreciation. This structure allows me to draw a distinction between capital intended as financial assets issued by firms and backed up by their earnings and capital intended as an intermediate good. As Judd [12] points out, much of the intuition behind the literature on optimal taxation of capital stems from the property that capital income is construed as the income to suppliers of the homogeneous (durable) intermediate good. This paper's structure allows me to keep the two features of capital separated and focus on dividends as the income paid to holders of financial assets. The reader, in particular, might want to observe that neither purchases nor sales of intermediate goods are taxed (see below).
} 
where $N$ is the mass of non-durable intermediate goods. These goods are vertically differentiated according to their quality. The productivity of $L_{i}$ workers using $X_{i}$ units of good $i$ depends on good $i$ 's quality, $Z_{i}$ and on average quality $Z=\int_{0}^{N} \frac{1}{N} Z_{j} d j$.

The final producer sets the value marginal product of intermediate good $i$ equal to its price, $P_{i}$, and the value marginal product of labor equal to the wage rate, $W$. This determines the demand curves

$$
\begin{aligned}
X_{i} & =\left(\frac{\theta}{P_{i}}\right)^{\frac{1}{1-\theta}} Z_{i}^{\alpha} Z^{1-\alpha} L_{i} \\
L_{i} & =\left(\frac{1-\theta}{W}\right)^{\frac{1}{\theta}} X_{i}\left(Z_{i}^{\alpha} Z^{1-\alpha}\right)^{\frac{1-\theta}{\theta}}
\end{aligned}
$$

The competitive final producer pays total compensation $\theta Y$ and $(1-\theta) Y$ to intermediate producers and labor, respectively.

\subsection{The corporate sector}

The typical intermediate firm produces its differentiated good with a technology that requires one unit of final output per unit of intermediate good and a fixed operating $\operatorname{cost} \phi Z_{i}^{\alpha} Z^{1-\alpha}$. The firm can invest units of final output to increase quality according to the technology

$$
\dot{Z}_{i}=R_{i},
$$

where $R_{i}$ is the firm's R\&D investment. Define the firm's gross cash flow (revenues minus production costs) as

$$
F_{i}=X_{i}\left(P_{i}-1\right)-\phi Z_{i}^{\alpha} Z^{1-\alpha},
$$

where $X_{i}$ is output, so that the firm's pre-tax profit is

$$
\Pi_{i}=F_{i}-R_{i} .
$$

The firm takes average quality $Z$ as given.

To highlight the role of taxation, let $\sigma$ be the fraction of R\&D expenditures that the firm is allowed to subtract from the gross cash flow to determine taxable income. ${ }^{4}$ The firm then pays total taxes

$$
t_{\Pi}\left(F_{i}-\sigma R_{i}\right),
$$

where $t_{\Pi}$ is the corporate income tax rate. It follows that

$$
D_{i}=\left(1-t_{\Pi}\right) F_{i}-\left(1-\sigma t_{\Pi}\right) R_{i}
$$

is the after-tax flow of dividends distributed by the firm to its stockholders. This expression makes clear that partial expensibility can be interpreted as taxation at rate $t_{\Pi}$ of fraction $1-\sigma$ of the

\footnotetext{
${ }^{4}$ Notice that in the US tax code R\&D is fully expensible. I assume partial expensibility because it allows me to make some interesting points concerning tax policy.
} 
R\&D undertaken by the firm or, equivalently, as subsidization at rate $\sigma t_{\Pi}$. This observation will be important later on in the interpretation of the results.

This formulation is adapted from Turnovsky [19] and corresponds to the "New View" in corporate finance and public economics, which holds that investment is financed internally and dividends are a residual. Auerbach [3] provides a detailed discussion of the New View and of the alternative "Old View", which holds that corporations finance investment by issuing new shares. Since both views are relevant to the issue studied in this paper, I first work out the model under the New View and then show, in Section 5, that I obtain the same qualitative results under the Old View.

Define the after-tax rate of return to equity as

$$
r=\left(1-t_{D}\right) \frac{D_{i}}{V_{i}}+\left(1-t_{V}\right) \frac{\dot{V}_{i}}{V_{i}},
$$

where $V_{i}$ is the price of firm $i$ 's shares, $t_{D}$ is the tax on distributed dividends and $t_{V}$ is the tax on capital gains. In equilibrium $r$ must equal the rate of return to saving obtained from the individual's maximization problem (see below) and thus is the same across firms. Integrating forward, this equation yields the after-tax value of the firm

$$
V_{i}(t)=\int_{t}^{\infty} e^{-\frac{\bar{r}(t, s)}{1-t_{V}} s} \frac{1-t_{D}}{1-t_{V}}\left[\left(1-t_{\Pi}\right) F_{i}(s)-\left(1-\sigma t_{\Pi}\right) R_{i}(s)\right] d s,
$$

where $\bar{r}(t, s) \equiv \frac{1}{s-t} \int_{t}^{s} r(v) d v$ is the average interest rate (return to saving) between $t$ and $s$. The firm chooses the time path of its product's price and R\&D in order to maximize this objective function subject to the demand schedule (2) and the technology constraints discussed above.

The firm undertakes $\mathrm{R} \& \mathrm{D}$ up to the point where the shadow value of the innovation, $q_{i}$, is equal to its cost,

$$
\frac{1-t_{D}}{1-t_{V}}\left(1-\sigma t_{\Pi}\right)=q_{i} \Leftrightarrow R_{i}>0 .
$$

Since the innovation is implemented in-house, its benefits are determined by the marginal after-tax profit it generates. Thus, the return to the innovation must satisfy the arbitrage condition ${ }^{5}$

$$
\frac{r}{1-t_{V}}=\frac{1-t_{D}}{1-t_{V}}\left(1-t_{\Pi}\right) \frac{\partial F_{i}}{\partial Z_{i}} \frac{1}{q_{i}}+\frac{\dot{q}_{i}}{q_{i}}
$$

To calculate the marginal profit, observe that the firm's problem is separable in the price and investment decisions. With demand (2) and marginal cost of production equal to one, the intermediate producer sets a price $P_{i}=\frac{1}{\theta}$. The firm's cash flow then is

$$
F_{i}=\left[\frac{1-\theta}{\theta} \theta^{\frac{2}{1-\theta}} L_{i}-\phi\right] Z_{i}^{\alpha} Z^{1-\alpha}
$$

and has the convenient property that

$$
\frac{\partial F_{i}}{\partial Z_{i}}=\alpha \frac{F_{i}}{Z_{i}} .
$$

\footnotetext{
5 The usual method of obtaining this condition is to write the Hamiltonian for the optimal control problem of the firm. The derivation in the text highlights the intuition.
} 
Substituting into (7) and imposing symmetry ${ }^{6}$ yields

$$
r=\left(1-t_{V}\right) \frac{1-t_{\Pi}}{1-\sigma t_{\Pi}} \alpha \frac{F}{Z} .
$$

Observe that the return to quality-improving R\&D, which is internal to the firm, does not depend on the tax on dividend income. The reason is that the firm treats dividends as a residual and thus its internal production/investment decisions are unaffected by taxation of the dividend income received by the stockholder.

The firms active at a given point in time must have been born at some earlier date. I now characterize the birth of the firm. A new firm wishing to set up operations at time $t$ must bear a sunk cost $\beta X_{i}(t)$ in units of final output. Because of this sunk cost, the new firm cannot supply an existing good in Bertrand competition with the incumbent monopolist, but must introduce a new good that expands product variety. I posit setup costs proportional to the new firm's initial output to capture in a simple way the idea that they depend on the productive assets that need to be put in place to start operations (structures and equipment). To fix terminology, I shall refer to the introduction of new products that expand the variety of intermediate goods and are brought to market by new firms as "entry".

Suppose that new firms finance entry by issuing equity. Entry is positive if the value of the firm is equal to its after-tax setup cost,

$$
V_{i}=\beta X_{i} \Leftrightarrow \dot{N}>0 .
$$

The post-entry profit that accrues to an entrant is given by the expression derived for the typical incumbent. Hence, the value of the firm satisfies the arbitrage condition (5). Taking logs and time derivatives of the free-entry condition (9) and imposing symmetry yields

$$
r=\left(1-t_{D}\right)\left[\left(1-t_{\Pi}\right) \frac{F}{\beta X}-\left(1-\sigma t_{\Pi}\right) \frac{R}{\beta X}\right]+\left(1-t_{V}\right) \frac{\dot{X}}{X} .
$$

Observe that this rate of return decreases with $t_{D} \cdot{ }^{7}$

\subsection{Households}

The economy is populated by a representative household whose (identical) members supply labor services and purchase financial assets (corporate equity) in competitive labor and asset markets. Each member is endowed with one unit of time and with preferences

$$
U(t)=\int_{t}^{\infty} e^{-(\rho-\lambda)(s-t)} \log u(s) d s, \quad \rho>\lambda \geqslant 0, \quad \gamma>0,
$$

\footnotetext{
${ }^{6}$ See Peretto $[14,15]$ for a discussion of the conditions under which it is reasonable to work with symmetric equilibria in models of this class. These conditions essentially reduce to the two requirements that (a) the firm-specific return to quality innovation is decreasing in $Z_{i}$ and (b) entrants enter at the average level of quality $Z$. The first implies that if one holds constant the mass of firms and starts the model from an asymmetric distribution of firm sizes, then the model converges to a symmetric distribution. The second requirement simply ensures that entrants do not perturb such symmetric distribution.

${ }^{7}$ The derivation of the return to equity in (10) posits that entry costs are not expensible. The Appendix shows that the paper's basic results remain qualitatively unchanged if entry costs are expensible.
} 
where

$$
\log u=\log C e^{-\lambda t}+\gamma \log (1-l)
$$

(To simplify the notation, I suppress time arguments whenever confusion does not arise.) $\rho$ is the individual discount rate. Initial population is normalized to one so that at time $t$ population size is $e^{\lambda t}$, where $\lambda$ is the rate of population growth. Instantaneous utility is defined over consumption per capita $C e^{-\lambda t}$ and leisure $1-l$, where $C$ is aggregate consumption and $l$ is the fraction of time allocated to work. $\gamma$ measures preference for leisure.

The household faces the flow budget constraint

$$
\dot{s} N V+s \dot{N} V=\left[\left(1-t_{D}\right) D-t_{V} \dot{V}\right] s N+\left(1-t_{L}\right) W l e^{\lambda t}-\left(1+t_{C}\right) C,
$$

where $s$ is the number of shares of each firm held by the household, $N$ is the number of firms, $D$ is the flow of dividends distributed by each firm, $\dot{V}$ is the appreciation of each firm's equity and $W$ is the wage rate. ${ }^{8}$ The government taxes labor income at rate $t_{L}$, dividends at rate $t_{D}$, capital gains at rate $t_{V}$, and consumption at rate $t_{C}$.

The optimal plan for this setup is well known. The household saves and supplies labor according to

$$
\begin{aligned}
& \rho-\lambda+\frac{\dot{C}}{C}=r=\left(1-t_{D}\right) \frac{D}{V}+\left(1-t_{V}\right) \frac{\dot{V}}{V}, \\
& L=l e^{\lambda t}=e^{\lambda t}-\frac{\left(1+t_{C}\right) \gamma C}{\left(1-t_{L}\right) W} .
\end{aligned}
$$

The Euler equation (11) defines the after-tax, reservation rate of return to saving that enters the evaluation of corporate equity discussed above.

\subsection{Government}

The government consumes final goods, cannot borrow and thus satisfies the budget constraint

$$
G=t_{L} W L+t_{C} C+t_{\Pi}(F-\sigma R) N+t_{D} D N+t_{V} \dot{V} N
$$

It is useful to characterize fiscal policy as

$$
G=g Y, \quad g<1 .
$$

The analysis below considers two cases. First, I consider a vector of fixed tax rates. Since $G$ is unproductive government consumption, this exercise shuts down the feedback of tax rate changes through the spending side of the budget and allows me to study the distortionary role of the five tax rates in isolation. In Section 4, in contrast, $g$ is fixed and one of the tax rates must adjust endogenously. This exercise, therefore, focuses on the effects of revenue-neutral changes in tax structure.

\footnotetext{
${ }^{8}$ I impose symmetry across firms in the budget constraint to keep the notation simple.
} 


\section{Equilibrium dynamics with fixed tax rates}

This section specifies fiscal policy as a vector of constant tax rates. Government consumption adjusts to balance the budget. It is useful to break down the general equilibrium system in two components: a block of equations characterizing labor and output market equilibrium that determine employment, output and the economy's saving ratio; a block characterizing the assets market that determines the allocation of saving across alternative investment opportunities on the quality-variety margin, and thus determines the economy's transition dynamics and long-run growth.

\subsection{Employment, output and saving}

Define the consumption ratio $c \equiv \frac{C}{Y}$, the (pre-tax) profit ratio $\pi \equiv \frac{\Pi N}{Y}$, the growth rate of quality $z \equiv \hat{Z}=\frac{R}{Z}$, and the number of firms per capita $n \equiv N e^{-\lambda t}$. (A hat on top of a variable denotes a proportional growth rate.) The labor supply equation (12) can be rewritten

$$
l=\frac{1}{1+\frac{\left(1+t_{C}\right) \gamma}{\left(1-t_{L}\right)(1-\theta)} c} .
$$

Recall that the labor market is competitive and clears instantaneously so that $l$ is the economy's employment ratio. In symmetric equilibrium (1) and (2) evaluated at price $P_{i}=\frac{1}{\theta}$ allow me to write

$$
Y=\Omega l e^{\lambda t} Z
$$

where $\Omega \equiv \theta^{\frac{2 \theta}{1-\theta}}$. This is the supply side of the output market. Equilibrium requires

$$
Y=G+C+N(X+\phi Z+R)+\beta X \dot{N},
$$

where $G$ is given by the government's budget constraint.

Now recall that substitution of the government's budget constraint into the economy's resources constraint yields the household's budget constraint. Add $N s \dot{V}$ to both sides of the constraint, divide through by $N s V$, and normalize the number of shares issued by each firm to 1 . The equilibrium relations for factor incomes, the relation $N X=\theta^{2} Y$, and the free entry condition $V=\beta X$, allow me to write

$$
\frac{\dot{Y}}{Y}=\left(1-t_{D}\right) \frac{D}{V}+\left(1-t_{V}\right) \frac{\dot{V}}{V}+\frac{\left(1-t_{L}\right)(1-\theta)-\left(1+t_{C}\right) c}{\beta \theta^{2}} .
$$

Finally, the Euler equation (11) allows me to rewrite this expression as

$$
\frac{\dot{c}}{c}=\left(1+t_{C}\right) \frac{1}{\beta \theta^{2}} c-(\rho-\lambda)-\left(1-t_{L}\right) \frac{1-\theta}{\beta \theta^{2}} .
$$

Since the tax rates $t_{C}$ and $t_{L}$ are constant, the consumption ratio jumps to the constant value

$$
c^{*}=\frac{(\rho-\lambda) \beta \theta^{2}+\left(1-t_{L}\right)(1-\theta)}{1+t_{C}} .
$$


Accordingly, the employment ratio jumps to

$$
l^{*}=\frac{1}{1+\gamma \frac{\left(1+t_{C}\right) c^{*}}{\left(1-t_{L}\right)(1-\theta)}}=\frac{1}{1+\gamma \frac{(\rho-\lambda) \beta \theta^{2}+\left(1-t_{L}\right)(1-\theta)}{\left(1-t_{L}\right)(1-\theta)}} .
$$

Thus, this economy exhibits the desirable property that at all points in time the (endogenous) saving ratio, $1-c^{*}$, is constant.

To understand why, observe that the assumption that the entry cost is proportional to the firm's initial output yields that the aggregate value of the securities issued by firms is proportional to aggregate output. Given logarithmic utility, the rate of return to stocks demanded (and earned) by savers implies that the household's budget constraint reduces to an unstable differential equation relating the rate of growth of the consumption ratio to its level. It follows that the unique equilibrium trajectory that satisfies boundary conditions is for the consumption ratio to jump to its steady-state value. This property simplifies greatly the analysis of transition dynamics. The reason is that the economy's saving ratio does not depend on the interest rate since log-utility implies that the substitution and income effects cancel out. This provides a convenient split between the consumption/saving decision of households, which generate the overall amount of resources available for investment, and the production/investment/entry decisions of firms, which determine the allocation of those resources across the two margins of technological advance, quality and variety. ${ }^{9}$

The derivation above uses the equilibrium conditions for the labor, output and assets markets, and the government's budget constraint. Recall that by assumption public spending does not affect output or utility. Hence, the government's budget constraint simply determines the amount of resources that the government subtracts from the system and can be ignored in the rest of this section's analysis. Section 5 brings the budget constraint back to the forefront and studies revenue-neutral changes in tax structure.

\subsection{The quality-variety trade-off in the assets market}

A useful consequence of the property that the saving ratio is constant is that the reduced-form, aggregate production function in (13) yields $\hat{Y}=z+\lambda$, while the fact that $c$ is constant yields $\hat{C}=\hat{Y}$. These two relations and the Euler equation (11) yield that the instantaneous reservation interest rate of savers is

$$
r=\rho+z .
$$

Given this rate, the interesting economic problem concerns the allocation of resources across quality and variety growth.

The returns to quality and variety growth characterized in the previous section, as well as the expression for pre-tax profit, contain the ratio of cash flow to quality, $\frac{F}{Z}$. The relation $N X=\theta^{2} Y$ and Eq. (13) allow me to write

$$
\frac{F}{Z}=\theta(1-\theta) \frac{\Omega l}{n}-\phi .
$$

\footnotetext{
9 One can relax the assumption of log utility and use preferences that feature (constant) intertemporal elasticity of substitution different from one, provided one preserve unitary elasticity of substitution between consumption and leisure. The Appendix shows the dynamical system that obtains in this case and argues that the paper's qualitative results remain the same. The cost is that the analysis of transitional dynamics, and thus of welfare, becomes more complicated.
} 
This term plays a key role in capturing the role of scale in this model. To show this, I proceed in steps.

First, I use (16) to rewrite the return to quality in (8) as

$$
r=\Psi \alpha\left[\theta(1-\theta) \frac{\Omega l}{n}-\phi\right]
$$

where $\Psi \equiv\left(1-t_{V}\right) \frac{1-t_{\Pi}}{1-\sigma t_{\Pi}}$. This expression shows that incentives to invest in quality improvements of existing products depend positively on the employment ratio, $l$, and negatively on the number of firms per capita, $n$. The reason is that higher employment shifts out the conditional demand for each intermediate good. This kicks in a cost-spreading effect at the firm level whereby the cost of quality-improving innovation is spread over more units of the good that the firm sells so that the unit cost of innovation is lower. By the same token, the return to quality-improving innovation decreases with the number of goods per capita because of the market share effect: the more goods there are, the more total demand for intermediates is spread thin across goods, and the weaker is the cost-spreading effect just discussed. Finally, the term $\Psi$ captures the distortionary effect of taxation of capital gains and profits on the firms' internal production/investment decisions. Note that $d \Psi / d t_{\Pi}<0$.

Next, I use (16) to rewrite the expression for pre-tax profit in (4) as

$$
\pi=\theta(1-\theta)-\frac{n(\phi+z)}{\Omega l^{*}}
$$

This expression highlights two important forces. First, the profit ratio is negatively related to quality growth because $R \& D$ is an endogenous fixed, sunk cost that the firm pays at any moment in time. Similarly, the fact that fixed overhead costs are linear in quality yields that the profit ratio falls with $\phi$. Second, the profit ratio is increasing in the employment ratio, $l$, and decreasing in the number of firms per capita, $n$, reflecting the cost-spreading and market-share effects discussed above.

I now observe that the employment ratio, $l$, is constant, take into account the non-negativity of $\mathrm{R} \& \mathrm{D}$, and then use (15) and (17), to write

$$
z(n)=\left\{\begin{array}{cc}
\Psi \alpha\left[\theta(1-\theta) \frac{\Omega l^{*}}{n}-\phi\right]-\rho, & n<\bar{n}, \\
0, & n \geqslant \bar{n},
\end{array}\right.
$$

where

$$
\bar{n} \equiv \frac{\Psi \alpha \theta(1-\theta) \Omega l^{*}}{\rho+\Psi \alpha \phi} .
$$

Finally, I use (16)-(19) to rewrite the return to equity in (10) as

$$
r=\left\{\begin{array}{cc}
\frac{\left(1-t_{D}\right)\left(1-t_{\Pi}\right)}{\beta \theta^{2}}\left[\theta(1-\theta)-\frac{n \phi}{\Omega l^{*}}-\frac{1-\sigma t_{\Pi}}{1-t_{\Pi}} \frac{z(n) n}{\Omega l^{*}}\right]+\left(1-t_{V}\right) \hat{X}, & n<\bar{n} \\
\frac{\left(1-t_{D}\right)\left(1-t_{\Pi}\right)}{\beta \theta^{2}}\left[\theta(1-\theta)-\frac{n \phi}{\Omega l^{*}}\right]+\left(1-t_{V}\right) \hat{X}, & n \geqslant \bar{n} .
\end{array}\right.
$$

This expression shows the role of the basic forces just discussed. The key is that the first term on the right-hand side is the after-tax dividend-price ratio, $\left(1-t_{D}\right) \frac{D}{V}$, that obtains after accounting for optimal R\&D decisions. Together, Eqs. (20) and (19) determine equilibrium of the assets market and the allocation of the economy's savings across quality AND variety growth. 


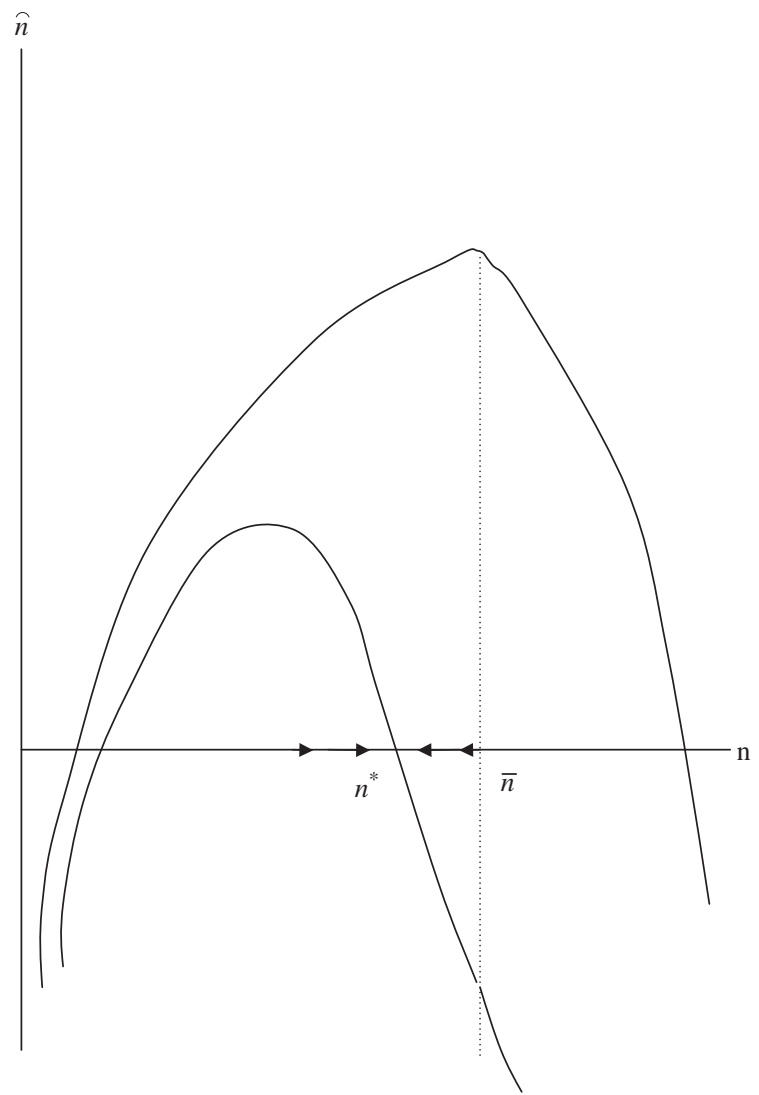

Fig. 1. Dynamics with fixed tax rates.

\subsection{The dynamical system}

To analyze dynamics, I use (15), (19) and the fact that $\hat{X}=z-\hat{n}$, to rewrite (20) as

$$
\hat{n}=\left\{\begin{array}{cl}
\frac{\left(1-t_{D}\right)\left(1-t_{\Pi}\right)}{\beta \theta^{2}\left(1-t_{V}\right)}\left[\theta(1-\theta)-\frac{n \phi}{\Omega l^{*}}-\frac{1-\sigma t_{\Pi}}{1-t_{\Pi}} \frac{z(n) n}{\Omega l^{*}}\right]-\frac{t_{V} z(n)+\rho}{1-t_{V}}, & n<\bar{n}, \\
\frac{\left(1-t_{D}\right)\left(1-t_{\Pi}\right)}{\beta \theta^{2}\left(1-t_{V}\right)}\left[\theta(1-\theta)-\frac{n \phi}{\Omega l^{*}}\right]-\frac{\rho}{1-t_{V}}, & n \geqslant \bar{n},
\end{array}\right.
$$

where $z(n)$ in the top line is given by (19). Fig. 1 illustrates the resulting dynamics.

The locus on the right-hand side of (21) is hump-shaped. Suppose that its maximum is in the region $n \geqslant \bar{n}$. Then for any initial condition $n(t)<\bar{n}$ the system features an accelerating entry rate until the economy crosses the threshold $\bar{n}$, quality-improving R\&D shuts down, and the economy converges to the steady state

$$
n_{0}=\left[\theta(1-\theta)-\frac{\rho \beta \theta^{2}}{\left(1-t_{\Pi}\right)\left(1-t_{D}\right)}\right] \frac{\Omega l^{*}}{\phi} .
$$


Suppose, in contrast, that the maximum of the locus is in the region $n<\bar{n}$. Then for any initial condition $n(t)<\bar{n}$, the entry rate eventually decelerates and the system can converge to a the steady state $n^{*}<\bar{n}$, where $n^{*}$ solves

$$
\frac{\left(1-t_{D}\right)\left(1-t_{\Pi}\right)}{\beta \theta^{2}\left(1-t_{V}\right)}\left[\theta(1-\theta)-\frac{n \phi}{\Omega l^{*}}-\frac{1-\sigma t_{\Pi}}{1-t_{\Pi}} \frac{z(n) n}{\Omega l^{*}}\right]=\frac{t_{V} z(n)+\rho}{1-t_{V}} .
$$

By construction, this solution features $z^{*}>0$. Inspection of the figure suggests that this steady state exists if $n_{0}<\bar{n}$, or

$$
\frac{1-\theta}{\beta \theta}<\frac{\rho+\left(1-t_{V}\right) \frac{1-t_{\Pi}}{1-\sigma t_{\Pi}} \alpha \phi}{\left(1-t_{\Pi}\right)\left(1-t_{D}\right)} .
$$

Recall that the ratio $\frac{1-\theta}{\beta \theta}=\frac{P(X-1)}{\beta X}$ is the ratio of the firm's revenues (minus variable costs) to setup cost. Hence, this condition says that the equilibrium with positive quality growth occurs if setup costs take up a sufficiently large fraction of revenues. This guarantees that the market does not become too crowded.

A simpler, and more insightful, characterization of dynamics in the region $(0, \bar{n})$ proceeds as follows. First, use (19) and (20) to calculate $z^{*}$ as the solution of a system that consists of (15), the reservation interest rate of savers, and

$$
r=\frac{1-\theta}{\beta \theta}\left(1-t_{D}\right)\left(1-t_{\Pi}\right) \frac{\rho+z\left[1-\left(1-t_{V}\right) \alpha\right]}{\rho+z+\Psi \alpha \phi}+\left(1-t_{V}\right) z,
$$

which characterizes the rate of return on investment delivered by the market. The upper panel of Fig. 2 illustrates the determination of the steady state in $(z, r)$ space as the intersection of the saving locus (15) and the investment locus (22). ${ }^{10}$ The lower panel illustrates dynamics in $(n, z)$ space.

The economy is at all times on Eq. (19), the downward sloping line in the figure. On the branch of (19) that lies above the steady-state locus, $z=z^{*}$, the economy experiences a rate of entry that is less that the rate of population growth so that the number of firms per capita shrinks. The reverse happens on the branch of (19) that lies below the steady-state locus. Notice, finally, that (19) yields

$$
n^{*}=\frac{\theta(1-\theta) \Psi \alpha \Omega l^{*}}{z^{*}+\rho+\Psi \alpha \phi} .
$$

As expected, the steady state $\left(n^{*}, z^{*}\right)$ is stable. To trace dynamics in response to changes in tax policy one simply needs to check how the change shifts the $z^{*}$ line and the instantaneous growth equation (19).

\subsection{The effects of tax rates}

Taxation of wages reduces both the consumption and employment ratios and has no effect on growth. Taxation of consumption reduces the consumption ratio and has no effect on the employment ratio and on growth. An important feature of the asset market equilibrium just characterized, in other words, is that it pins down steady-state growth independently of the scale factor $\Omega l$ and

\footnotetext{
${ }^{10}$ Notice that there are two solutions. The one with the smaller values of $z$ and $\pi$ is stable, the other one is unstable and can be ruled out; see the analysis of dynamics in Fig. 1.
} 

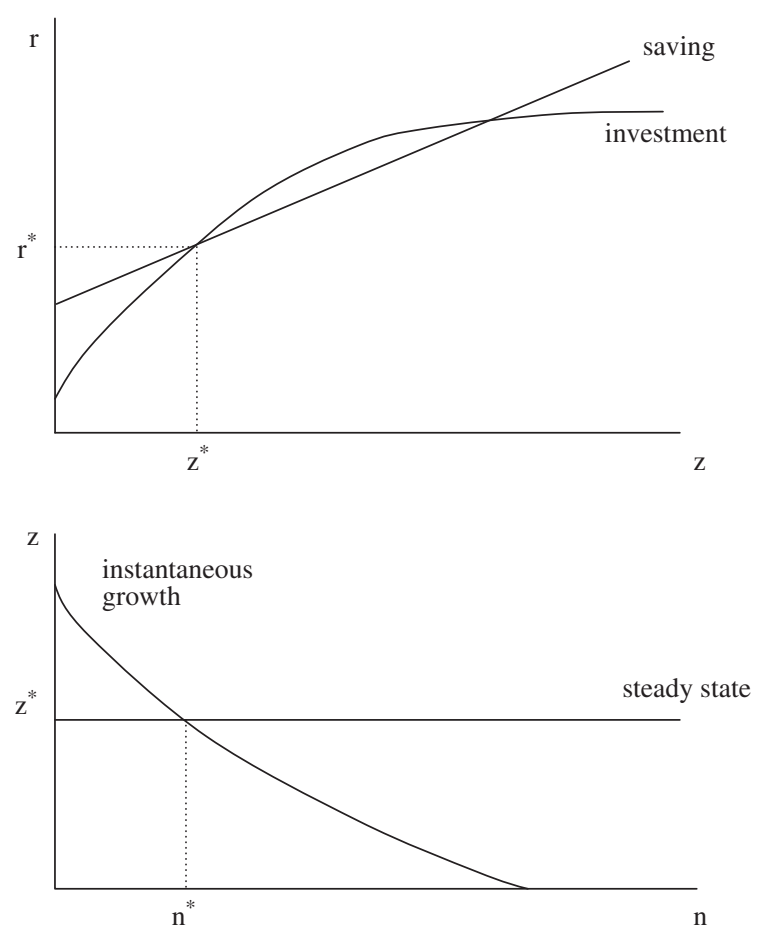

Fig. 2. Equilibrium with fixed tax rates.

thus of $t_{L}$ and $t_{C}$. It should be clear why: changes in fiscal variables that affect the employment ratio, $l^{*}$, are fully absorbed by the number of firms (product lines) per capita, see Eq. (23), so that the growth rate of quality remains unchanged. This result reflects the property that the model does not exhibit the scale effect because endogenous product variety sterilizes the effects of aggregate market size on the individual firm's incentives to innovate.

Taxation of dividends, capital gains and/or profits has no effect on the consumption and employment ratios. Recall that the reason behind this property is that these taxes govern the wedge between pre- and after-tax returns to saving whose effect on saving and labor supply is sterilized by the assumption of log utility. In the Appendix I argue that relaxing this assumption does not affect the qualitative results of the paper while it makes the analysis of dynamics and welfare harder. Assuming log-utility, on the other hand, has the advantage that it allows me to concentrate on how these taxes distort decisions on the quality-variety margin.

The tax on dividends has a positive effect on growth. The reason is that it does not affect the firms' internal R\&D decisions and thus it only affects the wedge between pre- and after-tax returns to equity. As a consequence, it shifts down the investment locus (22)—capturing the fact that the economy must generate a higher pre-tax dividend ratio to deliver to stockholders the required after-tax return on equity — and thus generates a movement along the saving locus (15) that produces faster growth. An important thing to notice in this regard is that the steady-state number of firms per capita $n^{*}$ decreases with $t_{D}$, see Eq. (23), so that, in line with conventional wisdom, taxing the returns to savings (the households equity holding) reduces the incentives to accumulation. The key is that the bulk of the adjustment is borne by lower product variety because that is how the individual product line earns a higher pre-tax profit. 
The tax on profits has an ambiguous effect on growth. This outcome depends on two forces. First, the distortion due to partial expensibility of R\&D shifts up the investment locus. (This is the term $\Psi$ on the right-hand side of (22).) The resulting movement along the saving locus produces slower growth. Opposite to this force is the wedge between the pre-tax and the aftertax return to equity that shifts down the investment locus. The resulting movement along the saving locus produces faster growth. Observe that the first force is sensitive to the assumptions concerning expensibility of R\&D. If R\&D is fully expensible (as in the US tax code), then $\sigma=1$ so that $\Psi=1-t_{V}$ and the distortionary effect of the corporate income tax on firms' internal $\mathrm{R} \& \mathrm{D}$ decisions disappears. In this case, the corporate income tax has a positive effect on growth, exactly like the dividend income tax. In fact, with full expensibility of R\&D taxation of profits and taxation of dividends are indistinguishable. The reason is that all costs borne by the firmvariable and fixed production costs plus $\mathrm{R} \& \mathrm{D}$ costs - are fully expensible so that taxing profits before or after distribution makes no difference. Another facet of this result is that expensibility of incumbents' R\&D costs implies an implicit subsidy at rate $t_{\Pi}$ that does not apply to entrants. ${ }^{11}$

Finally, the tax on capital gains, $t_{V}$, has the same qualitative effects as the corporate income tax just discussed, except that the distortion of firms' internal R\&D decisions does not depend on the expensibility parameter $(\sigma)$ and thus never vanishes.

\subsection{Welfare}

One of the desirable features of this model is the simple analysis of welfare it affords. I now turn to this feature. Let 0 be an arbitrary starting date. Taking into account that the consumption and employment ratios jump to their steady-state values, output per capita, $y \equiv Y e^{-\lambda t}$, at time $t>0$ is

$$
\log y(t)=\log \Omega l^{*}+\int_{0}^{t} z(s) d s+\log Z(0) .
$$

Without loss of generality I can normalize $Z(0) \equiv 1$. Using this expression, I can write the flow of utility inside the welfare function as

$$
\begin{aligned}
\log u(t) & =\log e^{-\lambda t} C(t)+\gamma \log (1-l(t)) \\
& =\log y(t)+\log c^{*}+\gamma \log \left(1-l^{*}\right) \\
& =\log \Omega l^{*}+\int_{0}^{t} z(s) d s+\log c^{*}+\gamma \log \left(1-l^{*}\right) .
\end{aligned}
$$

As one can see, the number of firms per capita, $n$, does not have a direct effect on income per capita, $y$, the consumption ratio, $c$, or the employment ratio, $l$. The reason why it matters is that given aggregate variables it determines firm-level variables and thus drives the dynamics of the interest rate and growth. The Appendix shows that relaxing this property and allowing for plausible social returns to variety does not change the basic results of the paper, while it makes the analysis harder.

\footnotetext{
${ }^{11}$ One might think, therefore, that the effects of the corporate income tax depend crucially on the assumption that the $R \& D$ expenditures of incumbents are expensible while the setup costs of entrants are not. In the Appendix I argue that this is not the case. I show that if the R\&D expenditures of incumbents and the setup costs of entrants receive symmetric fiscal treatment the results do not change. The reason is that as long as expensibility is only partial $(\sigma<1)$, identical nominal treatment of incumbents and entrants still gives rise to different effective subsidies implied by the corporate income tax. This is because R\&D decisions of incumbents are driven by marginal profits, whereas entry decisions are driven by full profits.
} 
Flow utility features a tension between work and leisure. The following result allows me to resolve this tension.

Lemma 1. Holding constant the consumption ratio c, flow utility is increasing in the employment ratio $l$.

Proof. See the Appendix.

With this result in hand, I can now analyze the effects of taxes. I limit the discussion to two examples. First, consider a reduction in the labor income tax. According to the discussion above, this change does not affect steady-state quality growth. Thus, in Fig. 2 the flat steady-state growth locus $z^{*}$ does not move. On the other hand, the tax cut induces people to work more so that labor supply and employment rise. Moreover, because it raises after-tax labor income, the tax cut raises the consumption ratio. Now notice that the higher employment ratio shifts up the downward sloping instantaneous growth locus. (Recall that the employment ratio jumps instantaneously to its steady-state value.) As a result, the economy experiences a transition characterized by permanently higher employment and consumption ratios and temporarily faster than trend quality and variety growth. For the former, the baseline trend is the value $z^{*}$. For the latter, the baseline trend is the growth rate of population $\lambda$. Now, according to Lemma 1 the rise in the employment and consumption ratios raise welfare. On top of these level effects, there is the temporarily faster growth of quality which implies that at the end of the transition the level of productivity is higher. This is important: this tax cut does not change the steady-state growth rate so that its welfare benefits stem from level effects.

Contrast this with a reduction of the dividend income tax. The consumption and employment ratios do not change so that there are no level effects. Moreover, the instantaneous growth locus does not shift because this tax does not distort the internal decisions of firms. Hence, the only effect of this tax cut is to shift down the steady-state growth locus $z^{*}$. The resulting transition is characterized by a gradual slowdown of quality growth and by temporarily faster than trend variety growth. It follows that the welfare effects of this tax instrument stem exclusively from the quality-variety trade-off characterizing this model. Since in this setup there are zero social returns to variety, the welfare effect of this transition is negative. In other words, the reason why the dividend tax cut reduces welfare is that it reduces growth by raising product variety and thereby diluting investment resources on a larger mass of products per capita.

As mentioned above, the Appendix shows that this qualitative result is robust to the introduction of plausible social returns to variety. Given this robustness, a natural question to ask is: what is the "deep" reason why one should expect the dividend tax to raise welfare? Is there an externality hiding behind the quality-variety trade-off that the market fails to internalize? The answer is: yes, there is. Entrants fail to take into account that by expanding product variety they dilute the incentives of inframarginal firms to invest in the growth of their product lines. The tax on dividends corrects the situation by penalizing entry—relative to incumbent growth — and thereby weakening the associated dilution effect. The next section illustrates how this insight suggests some new, intriguing perspectives for tax policy.

\section{Revenue-neutral changes in fiscal policy}

Section 3 has characterized the effect of a given tax structure on the growth path of the economy. This section considers the case of endogenous tax rates. To bring out the novel aspects of the model, 
I focus on changes in fiscal policy that reduce taxation of wages, consumption, profit or capital gains making up the revenue shortfall with an increase in the tax on dividends.

\subsection{The government's budget and the role of taxes on profits, dividends and capital gains}

Let $T \equiv g-t_{L}(1-\theta)-t_{C} c^{*}$. The government's budget constraint then reads

$$
T=\left[t_{\Pi}+t_{D}\left(1-t_{\Pi}\right)\right] \pi+t_{\Pi}\left(1-t_{D}\right)(1-\sigma) \frac{N R}{Y}+t_{V} \beta \theta^{2} \hat{X} .
$$

Observe that $T$ defines the revenue flow that taxation of profits, dividends and capital gains must generate. The right-hand side of this expression emphasizes two things. First, the effective tax rate on profits is $t_{\Pi}+t_{D}\left(1-t_{\Pi}\right)$; this is the well-known double taxation of dividends. Second, the last two terms capture taxation of growth through two channels. The first is obvious: partial expensibility implies that fraction $1-\sigma$ of the firm's R\&D is taxed at rate $t_{\Pi}$. The reason why the government's revenue generated by this tax is multiplied by $1-t_{D}$ is that earnings that the firm retains to finance $R \& D$ do not get taxed as distributed dividends. The second channel is the tax on capital gains, which in fact is a tax on the firm's growth. The reason is that the free-entry condition pins down the value of the firm's shares as proportional to the firm's size which, in turn, is proportional to the quality of its good.

To highlight these features, I use expressions for $\pi, z$ and $\hat{n}$ derived above to rewrite the budget constraint as

$$
\begin{aligned}
T= & \frac{t_{\Pi}+t_{D}\left(1-t_{\Pi}\right)-t_{V}}{1-t_{V}} \theta(1-\theta) \frac{\rho+z(1-\Psi \alpha)}{\rho+z+\Psi \alpha \phi} \\
& +\frac{1}{1-t_{V}} z\left[t_{V} \beta \theta^{2}+t_{\Pi}\left(1-t_{D}\right)(1-\sigma) \frac{\theta(1-\theta) \Psi \alpha}{\rho+z+\Psi \alpha \phi}\right]+\frac{t_{V}}{1-t_{V}} \rho \beta \theta^{2} .
\end{aligned}
$$

Recall now that in this exercise $T$ is constant so that this expression determines the endogenous tax rate $t_{D}$ as a function of the growth rate $z$. The right-hand side defines the dividend-tax revenue curve. Observing that the optimal R\&D decisions of firms imply that $z$ depends on $\pi$, this expression allows me to highlight that $t_{D}, t_{V}, t_{\Pi}$ are just different ways of taxing the same underlying income flow, $\pi$, from the firms' productive assets. However, because they introduce different distortions their welfare effects differ.

An interesting feature of this characterization of the government's budget constraint is that it identifies two classes of reforms in corporate tax policy: (a) reforms that do not change $T$, the required revenue flow that taxation of the firms' net cash flow must deliver, but change the relative importance of $t_{D}, t_{\Pi}$ and $t_{V}$ in generating that revenue, and (b) reforms that change $T$.

\subsection{Experiments}

Substitution of the government budget constraint into the expression for the rate of return to entry, Eq. (20), yields

$$
(\hat{n}+\rho) \beta \theta^{2}=\pi-T .
$$

This allows for a very simple characterization of dynamics. I focus on the equilibrium path in the region $(0, \bar{n})$ where $z>0$. First, observe that $\hat{n}=0$ implies

$$
\pi^{*}=\rho \beta \theta^{2}+T .
$$



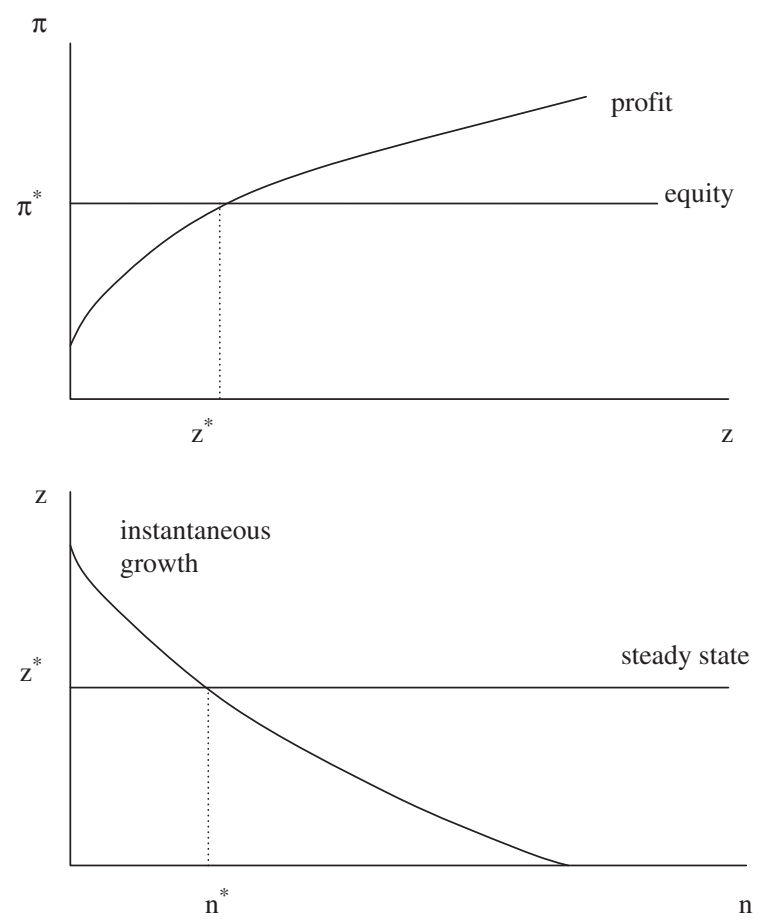

Fig. 3. Equilibrium with endogenous dividend tax rate.

Using (15), (17) and (18) yields

$$
z^{*}=\frac{\phi(1-\alpha \Psi \Gamma)-\rho \Gamma}{\Gamma-1}, \quad \frac{\phi}{\rho}>\Gamma>1,
$$

where

$$
\Gamma \equiv \frac{1}{\Psi \alpha}\left[1-\frac{\rho \beta \theta^{2}+T}{\theta(1-\theta)}\right] .
$$

Thus, $z^{*}$ is the steady-state growth rate that delivers the required rate of return to stockholders. Finally, $n^{*}$ is given by evaluating (19) at this value $z^{*}$; see Eq. (23).

The analysis of dynamics is similar to the case of exogenous tax rates. Consider Fig. 3. The economy is at all times on Eq. (19), the downward sloping line. The steady state $\left(n^{*}, z^{*}\right)$, given by the intersection of (19) and (27), is stable.

Policies of class (a) defined above, those that do not change $T$, shift both the growth equation (19) and the $z^{*}$ line through the term $\Psi$. Policies of class (b) that change $T$ because they change $t_{L}, t_{C}$, shift the growth equation (19) through the scale factor $l$ and shift the $z^{*}$ line because they change the profit ratio that must arise in equilibrium to deliver to stockholders their required aftertax rate of return. This feature highlights that policies of class (a) operate directly by reducing distortions of the production/investment choices of firms and indirectly by distorting decisions on the quality-variety margin through the endogeneity of the tax on dividends. Policies of class 
(b) operate directly through the size of the market and indirectly through the endogeneity of the tax on dividends.

I summarize comparative statics results as follows.

Proposition 2. When the government balances the budget by setting endogenously the tax rate on dividend income, steady-state quality growth, $z^{*}$, is decreasing in the tax rates on labor, consumption, capital gains and profits, $t_{L}, t_{C}, t_{V}, t_{\Pi}$, and is increasing in the expensibility parameter, $\sigma$. Steady-state product variety, $n^{*}$, is increasing in the tax rate on consumption, $t_{C}$, and is decreasing in the expensibility parameter, $\sigma$. The effects of the tax rates on labor, profits and capital gains, $t_{L}, t_{\Pi}, t_{V}$ on $n^{*}$ are ambiguous.

Proof. Differentiate (23) and (27).

The reason why increases in taxes on wages and/or consumption generate a decrease of the growth rate is of course that those taxes have no direct effect on growth, while their indirect effect is to decrease the dividend income tax which reallocates resources from quality growth to variety expansion. More intriguing is the reason why increases in taxes on profits and capital gains, which have ambiguous direct effects on growth and the number of firms, now unambiguously reduce growth and raise the number of firms. The key is the different steady-state locus that applies in this exercise, Eq. (26), that shows how increases in $t_{\Pi}$ or $t_{V}$ are offset in the government's budget constraint by reductions in $t_{D}$, which reduce growth. Similarly, growth is increasing in $\sigma$, which is a subsidy to incumbents' $R \& D$, because the expenditure is financed with an increase of the dividend income tax which reinforces the pro growth effect of the subsidy. This property has surprising welfare implications, to which I now turn.

To fix a benchmark for comparison, let a star denote steady-state values of the endogenous variables for an arbitrary initial vector $\sigma, t_{L}, t_{C}, t_{\Pi}, t_{V}$, and let a double star denote values produced by the posited change in fiscal policy.

Proposition 3. A revenue-neutral introduction of full expensibility of corporate firms' $R \& D(\sigma=$ 1) financed with an increase of the dividend income tax is welfare improving. A revenue-neutral elimination of taxation of corporate profits and of capital gains on corporate equity holdings $\left(t_{\Pi}=t_{V}=0\right)$ financed with an increase of the dividend income tax is welfare improving.

Proof. These policies belong to category (a) discussed above. They leave $T$ unchanged and eliminate distortions of the production/investment choices of firms so that $\Psi=1$. When the change of tax structure takes place, $c$ and $l$ remain at $c^{*}$ and $l^{*}$. Given the initial condition $n^{*}$, transition dynamics feature a gradual decline toward $n^{* *}$. The growth rate $z$ jumps up and then rises gradually toward $z^{* *}$. This change in tax structure improves welfare because it has no level effects while it raises growth permanently. Formally, for a policy implemented at time $t=0$ the change in welfare is

$$
\Delta U_{0}=\int_{0}^{\infty} e^{-(\rho-\lambda) t} \log \frac{u(t)}{u^{*}} d t
$$

where flow utility relative to the initial steady state is

$$
\log \frac{u(t)}{u^{*}}=\log \frac{y(t)}{y^{*}} .
$$


Let $\hat{y}$ denote the instantaneous rate of growth of income per capita. Along the transition, then,

$$
y(t)=y^{*} e^{\int_{0}^{t} \hat{y}(s) d s} .
$$

Therefore,

$$
\begin{aligned}
\log \frac{y(t)}{y^{*}} & =\int_{0}^{t}\left[\hat{y}(s)-\hat{y}^{*}\right] d s \\
& =\int_{0}^{t}\left[r(s)-r^{*}\right] d s .
\end{aligned}
$$

The second line of this expression makes clear that the policy improves welfare because it raises the after-tax rate of return to innovation.

Proposition 4. A revenue-neutral reduction of the tax rates on labor income and/or consumption financed with an increase in the dividend income tax is welfare improving.

Proof. These policies belong to category (b) discussed above. They raise $T$ and the scale factor $\Omega l$. When the government reduces $t_{L}$ and/or $t_{C}$, the consumption and employment ratios jump to $c^{* *}>c^{*}$ and $l^{* *}>l^{*}$, respectively, since the policy reduces the distortions of the households' consumption/leisure and labor/leisure decisions. Accordingly, the downward sloping growth locus (19) in Fig. 3 shifts up as firms respond to the larger market size by pursuing quality improvements more aggressively (this transitory scale effect is characteristic of models of this class). The economy then experiences an initial jump up in the growth rate $z$ followed by either a decrease or an increase. The reason is that the effect of the change in tax structure on the number of firms per capita is ambiguous due to two competing effects. First, the dividend income tax discriminates against entry in favor of quality growth. Second, the larger market created by these policies attracts entry. This effect is regulated by the response of labor supply to tax rates. If the net effect is to raise the number of firms per capita, the growth rate of quality overshoots the steady-state level and converges to its long-run level from above. In the opposite case, it converges from below. In both cases the economy experiences a permanent acceleration of the growth rate of quality. This policy improves welfare because it increases the consumption and employment ratios and it raises the return to innovation. Following the procedure of the previous proposition, the relative change in flow utility is

$$
\log \frac{u(t)}{u^{*}}=\log \frac{l^{* *}}{l^{*}}+\log \frac{c^{* *}}{c^{*}}+\gamma \log \frac{1-l^{* *}}{1-l^{*}}+\int_{0}^{t}\left[r(s)-r^{*}\right] d s .
$$

As in the case above, integration yields the change in welfare.

Propositions 3 and 4 suggest that the posited policies are desirable since they increase welfare. A natural question is: are they feasible, that is, do they satisfy the constraint $0<t_{D}<1$ ? Recall that solving for $t_{D}$ requires solving Eq. (24). Recall that the right-hand side of the equation defines the dividend tax revenue curve. This curve has a positive intercept at $t_{D}=0$. Thus, if $T$ is sufficiently low and/or $t_{\Pi}$ and $t_{V}$ are sufficiently high it is possible to obtain a solution $t_{D} \leqslant 0$. This uninteresting case can be ruled out by a suitable choice of the initial vector $\sigma, t_{L}, t_{C}, t_{\Pi}, t_{V}$. It is more interesting to check whether $t_{D} \geqslant 1$ can occur. To simplify matters, observe that $t_{D}$ is highest when $t_{V}=t_{\Pi}=0$, in which case the budget constraint yields $T=t_{D} \pi(z)$ so that $t_{D}<1$ requires $T<\pi(z)$. If a policy is feasible in this case, it is surely feasible in the case $t_{V}, t_{\Pi}>0$ 
Consider now a policy that raises $T$ to $T+\Delta T$ and sets $t_{V}=t_{\Pi}=0$. Transition dynamics in response to this policy exhibit an initial jump up in $\pi$ due to the elimination of $t_{\Pi}$ and $t_{V}$, see Eq. (18), and an initial jump up in $z$ due to the shift up of the growth equation (19). Two cases are possible. If $n^{* *}>n^{*}, z$ overshoots the new steady-state level and converges to $z^{* *}$ from above. Accordingly, $\pi$ is lowest, so that $t_{D}$ is highest, at the end of the transition. The feasibility condition then is

$$
T+\Delta T<\pi^{* *}=\rho \beta \theta^{2}+T+\Delta T,
$$

which is obviously satisfied. Things are harder when $n^{* *}<n^{*}$, because $z$ undershoots so that $\pi$ is lowest, and $t_{D}$ is highest, at the beginning of the transition. Taking into account that $\pi$ jumps initially so that $\pi(z)>\pi^{*}$, the feasibility condition is

$$
T+\Delta T<\pi^{*}=\rho \beta \theta^{2}+T<\pi(z) .
$$

Therefore, one needs to check that the parametric restriction $\Delta T<\rho \beta \theta^{2}$ is satisfied. This is obviously true if $\Delta T=0$ as in Proposition 3 .

The conclusion of this analysis is that the policy in Proposition 3 is surely feasible, while a sufficient condition for feasibility of the policy in Proposition 4 is $n^{* *}>n^{*}$, that is,

$$
\frac{l^{* *}}{l^{*}}>\frac{\theta(1-\theta)(1-\alpha)-T-\rho \beta \theta^{2}}{\theta(1-\theta)[1-\alpha \Psi]-T-\Delta T-\rho \beta \theta^{2}} .
$$

On the right-hand side of this inequality is the relative increase in the tax pressure on the firms' cash flow, which requires the profit ratio $\pi$ to rise, so to expand the tax base, and thus requires the number of firms per capita to fall. On the left-hand side of the inequality is the relative increase in market size that allows the profit ratio $\pi$ to rise even if $n$ rises. The inequality, therefore, says that the number of firms per capita rises if the market size effect dominates.

\section{Assessment and interpretation}

Before concluding, it is useful to make an assessment of the results, paying particular attention to their robustness to alternative assumptions concerning some key aspects of my framework. It is also useful to provide an interpretation of the mechanism driving the model.

\subsection{Robustness}

A literal reading of the model set up in Section 2 might lead one to conclude that the qualityvariety trade-off delivers surprising results concerning corporate taxes because different agents operate on its two sides: quality growth is driven by the internal R\&D decisions of existing firms; variety growth is driven by the entry decisions of new firms.

What happens, one might ask, if one changes the model's long-run engine of growth from one of "creative accumulation" to one of "creative destruction" whereby quality-improving innovations are brought to market by newborn firms that replace current incumbents? In such an environment, there is no R\&D decision internal to the firm and the mechanism discussed above might fail because all innovators are entrants.

Upon reflection, this question is just a roundabout way of getting at the fact that in my framework the different agents on the two margins of the quality-variety trade-off use different financing instruments: incumbents finance quality-improving $R \& D$ out of retained earnings while entrants 
finance setup costs by issuing equity shares. As mentioned in Section 2, this is consistent with the New View that corporations finance investment out of retained earnings and dividends are a residual. Checking the robustness of my results then requires working out my model of creative accumulation under the Old View that corporations finance investment by issuing new shares. The main implication of this change is that under the Old View dividend taxes distort internal R\&D decisions and thus discourage quality growth so that, in principle, there is a tension between the distortionary effects on the two margins of the quality-variety trade-off.

It turns out, however, that in my model this tension can be resolved so that the growth effect of the dividend tax remains unambiguously positive. I just sketch the argument here since the analysis is basically identical to the one undertaken above. I also assume no expensibility of R\&D $(\sigma=0)$ to simplify the relevant expressions. Again adapting the formulation in Turnovsky [19], under the Old View the objective function of the typical firm is

$$
V_{i}(t)=\int_{t}^{\infty} e^{-\frac{\bar{r}(t, s)}{1-t_{V}} s}\left[\frac{1-t_{D}}{1-t_{V}}\left(1-t_{\Pi}\right) F_{i}(s)-R_{i}(s)\right] d s,
$$

where $\bar{r}(t, s) \equiv \frac{1}{s-t} \int_{t}^{s} r(v) d v$ is the average interest rate (return to saving) between $t$ and $s$ and in my notation $F_{i}(s)$ is the gross cash flow (revenues minus production costs). It is useful to rewrite this expression as

$$
V_{i}(t)=\int_{t}^{\infty} e^{-\frac{\bar{r}(t, s)}{1-t_{V}} s} \frac{1-t_{D}}{1-t_{V}}\left[\left(1-t_{\Pi}\right) F_{i}(s)-\frac{1-t_{V}}{1-t_{D}} R_{i}(s)\right] d s .
$$

This differs from the expression that applies under the New View only by the factor $\frac{1-t_{V}}{1-t_{D}}$ inside the bracket. This factor captures the after-tax cost of financing a dollar worth of R\&D by issuing shares (as opposed to retained earnings). The analysis is then qualitatively identical to that of the previous section except that now rate of return to internal $R \& D$ is

$$
r=\left(1-t_{D}\right)\left(1-t_{\Pi}\right) \alpha \frac{F}{Z}
$$

Observe that the tax that distorts R\&D decisions is now $t_{D}$ instead of $t_{V}$. Proceeding as in the previous section, the Old View investment locus is

$$
r=\frac{1-\theta}{\beta \theta}\left(1-t_{D}\right)\left(1-t_{\Pi}\right) \frac{\rho+z\left[1-\left(1-t_{V}\right) \alpha\right]}{\rho+z+\left(1-t_{D}\right)\left(1-t_{\Pi}\right) \alpha \phi}+\left(1-t_{V}\right) z .
$$

Using the definition of $\Psi$ under $\sigma=0$ allows me to rewrite (22), the New View investment locus, as

$$
r=\frac{1-\theta}{\beta \theta}\left(1-t_{D}\right)\left(1-t_{\Pi}\right) \frac{\rho+z\left[1-\left(1-t_{V}\right) \alpha\right]}{\rho+z+\left(1-t_{V}\right)\left(1-t_{\Pi}\right) \alpha \phi}+\left(1-t_{V}\right) z .
$$

As one can see, the two expressions differ only by the factors capturing the distortion of internal R\&D decisions that appear in front of $\alpha \phi$ in the denominator: under the Old View, the distortion is given by $\left(1-t_{D}\right)\left(1-t_{\Pi}\right)$; under the New View, it is given by $\left(1-t_{V}\right)\left(1-t_{\Pi}\right)$. More importantly, despite the fact that under the Old View there is a tension between the distortionary effects of dividend taxation on the intensive and extensive margins, the return to equity is decreasing in $t_{D}$ for given $z$. As a consequence, under both views the growth effect of dividend taxation is positive. 
The logic behind this result explains why I reach the same conclusion when I change the engine of growth of the model to creative destruction. From the viewpoint of this paper, the key feature of creative destruction is not that new firms - as opposed to existing ones-bring to market quality improvements but that they finance this activity by issuing shares. It is the financial instrument that matters, not who does the investment (an incumbent $v s$. a challenger). I wish to add to this argument some observations that further support my focus on creative accumulation. First, most product-specific innovations (in particular of the incremental type discussed here) are brought to market by existing, well-established firms. Hence, my creative accumulation model is empirically more relevant than the creative destruction version. Second, when all innovations are brought to market by new firms there is no longer an interesting role for the corporate income tax and the expensibility of $R \& D$ since there is no internal $R \& D$ decision to speak of. Third, creative destruction makes the analysis much more cumbersome, while a main attraction of my model is its tractability. Fourth, the cumulative view of technology that I adopt here produces a model very much in line with the traditional analysis of corporate taxation and business investment based on the neoclassical model of capital accumulation (see, e.g., [7,19]). The fundamental difference is that in my framework firms accumulate intangibles and the market structure is not competitive.

\subsection{Interpretation}

To interpret this model's mechanism, it is useful to focus on Fig. 2 and the definition of the after-tax return to equity, reproduced below for convenience

$$
r=\left(1-t_{D}\right) \frac{D}{V}+\left(1-t_{V}\right) \frac{\dot{V}}{V}
$$

This equation says that the firm delivers the reservation interest rate to savers through two components: after-tax dividends and after-tax capital gains. When dividends are taxed, the firm needs to raise the pre-tax dividend-price ratio, $D / V$, and/or the capital gains, $\dot{V} / V$. In equilibrium, both of these components are increasing functions of the rate of growth of quality, $z$; see the expressions discussed above for the Old and New Views. It follows that with taxation of dividends financial market equilibrium requires a reallocation of investment effort toward the growth component of the return to equity because that's how firms can keep delivering to savers their reservation rate of return. The key then is Eq. (19), which says that firms are willing to raise the growth rate of quality when product variety falls. This is because demand becomes more concentrated and firms can exploit more the cost-spreading effect discussed above. The required reduction in the number of products per capita, therefore, embodies the model's key insight that taxation of dividends reallocates resources from product proliferation to quality growth.

As discussed in the Introduction, in this model product proliferation is the activity with low growth opportunity because in the presence of fixed operating costs the number of products is constrained by the size of the workforce, so that in the horizontal dimension of technology space steady-state growth independent of (exogenous) population growth is not possible. In the vertical dimension, in contrast, steady-state growth is feasible because progress along the quality ladder does not require the replication of fixed costs. This property suggests the following interpretation: Taxation of dividends induces the financial market to reallocate resources away from the investment activity with low growth opportunity and toward the investment activity with high growth opportunity. Depending on how one sets up the specific model, this reallocation can take the form 
of shifting funds from entrants to incumbents - as in the literal reading of my model alluded to above — or from variety entrants to quality entrants—as in the creative destruction version of the model.

\section{Conclusion}

In this paper, I have investigated the role of taxation in a very tractable Schumpeterian growth model that assigns a central role to the corporation viewed as a long-lived profit center that brings a continuous flow of innovations to the market. These features make the model very useful for thinking about distortionary taxes, in particular taxes on corporate activity.

The prediction that the dividend income tax raises growth and welfare is perhaps surprising. On close inspection, however, it rests on a straightforward intuition: Taxation of dividends induces the financial market to reallocate resources from the investment activity with low growth opportunity to the investment activity with high growth opportunity in order to ensure that the rate of return delivered by firms keeps matching the consumers' reservation rate of return on saving. Specifically, the dividend income tax requires firms to raise the pre-tax dividend/price ratio and/or the after-tax capital gain components of the return that they deliver to stockholder in order to match his reservation after-tax rate of return. This, in turn, requires that firms raise the growth rate of future earnings by investing more in quality growth. Crucially, firms are willing to raise the growth rate of quality within each product line when overall product variety falls. This is because demand becomes more concentrated and firms can exploit more effectively the cost-spreading effect associated to (exogenous) fixed operating costs and (endogenous) fixed R\&D costs. This reduction in the number of products per capita embodies the model's key insight that taxation of dividends reallocates resources from product proliferation to quality growth. This is important, because product proliferation is the activity with low growth opportunity. The reason is that fixed operating costs imply that the number of products is constrained by the size of the workforce, so that in the horizontal dimension of technology space steady-state growth independent of (exogenous) population growth is not possible. In the vertical dimension, in contrast, steady-state growth is feasible because progress along the quality ladder does not require the replication of fixed costs.

This mechanism has interesting implications for the role of other distortionary taxes—on labor, consumption, or corporate profits - and for revenue-neutral changes in fiscal policy. For example, I showed that reduction of taxes on labor, consumption and/or (pre-distribution) corporate profits financed with increases in the tax rate on dividend income (distributed profits) raise growth and welfare.

This analysis is particularly relevant to the current debate. One argument in support of the Job Growth and Taxpayer Relief reconciliation Act of 2003 (JGTRRA) that is based on conventional economic wisdom is that the substantial reduction of tax rates on distributed dividends will reduce the corporate cost of capital and thereby increase investment. This paper's analysis suggests that things are not so straightforward in an environment where market structure matters. The growth and welfare effects of such interventions depend crucially on how they affect the financial market's allocation of funds between the vertical (quality/productivity) and horizontal (variety) dimensions of technological advance. It is the latter, extensive margin that produces the novel results of this paper. Taking this margin seriously requires us to rethink some of the conventional wisdom underlying basic propositions concerning the role of corporations and of corporate taxation in the macroeconomy. 


\section{Acknowledgments}

I thank an anonymous referee and an Associate Editor for their helpful comments.

\section{Appendix A.}

\section{A.1. Proof of Lemma 2}

Holding constant $c$, flow utility is increasing in $l$ if $l<\frac{1}{1+\gamma}$. Observing that the largest possible value of the employment ratio obtains for $t_{L}=t_{C}=0$, a sufficient condition for utility to be increasing in $l$ is

$$
l_{t_{L}=t_{C}=0}^{*}=\frac{1}{1+\gamma \frac{(\rho-\lambda) \beta \theta^{2}+1-\theta}{1-\theta}}<\frac{1}{1+\gamma},
$$

which implies

$$
(\rho-\lambda) \beta \theta^{2}+1-\theta>0 .
$$

This inequality holds because $\rho>\lambda$ is necessary to have bounded utility. It follows that the steady states occur on the upward sloping portion of the flow utility function with respect to the employment rate.

\section{A.2. General CIES preferences}

Suppose that flow utility takes the form

$$
\frac{\left[C(1-l)^{\gamma}\right]^{1-\xi}-1}{1-\xi}, \quad \xi>0 .
$$

As is well known, the case analyzed in the text obtains for $\xi=1$. The Euler equation for consumption now reads

$$
\begin{aligned}
r & =\xi \hat{C}+\rho \\
& =(\xi-1) \hat{C}+\hat{C}+\rho .
\end{aligned}
$$

Substituting into the household's budget constraint as I did in the text yields

$$
\begin{aligned}
0 & =(\xi-1) \hat{C}+(\hat{C}+\lambda-\hat{Y})+\rho-\lambda+\frac{\left(1-t_{L}\right)(1-\theta)-\left(1+t_{C}\right) c}{\beta \theta^{2}} \\
& =\frac{\xi-1}{\xi}(r-\rho)+\hat{c}+\rho-\lambda+\frac{\left(1-t_{L}\right)(1-\theta)-\left(1+t_{C}\right) c}{\beta \theta^{2}} .
\end{aligned}
$$

Now recall that Eq. (17) characterizes $r$ as a function of $n$ and $l$, which is a function of $c$. These facts allow me to write

$$
\hat{c}=-\frac{\xi-1}{\xi}[r(n, c)-\rho]-(\rho-\lambda)-\frac{\left(1-t_{L}\right)(1-\theta)-\left(1+t_{C}\right) c}{\beta \theta^{2}},
$$


where

$$
\begin{aligned}
& r(n, c)=\Psi \alpha\left[\theta(1-\theta) \frac{\Omega l(c)}{n}-\phi\right], \\
& l(c)=\frac{1}{1+\frac{\left(1+t_{C}\right) \gamma}{\left(1-t_{L}\right)(1-\theta)} c} .
\end{aligned}
$$

As one can see, the consumption ratio is not constant at all times because the substitution and income effects of changes in the interest rate do not cancel out. Nevertheless, one can study dynamics in $(n, c)$ space in the conventional manner. In the case of Propositions 3 and 4, for example, Eq. (25) used in the text still applies with the difference that because $c$ is not constant, I need to write it as

$$
\beta \theta^{2}(\rho+\hat{n})=\pi(n, c)-\left[g-t_{L}(1-\theta)-t_{C} c\right],
$$

where

$$
\begin{aligned}
& \pi(n, c)=\left\{\begin{array}{cc}
\theta(1-\theta)[1-\alpha \Psi]-\frac{(\phi-\rho) n}{\Omega l(c)}, & n<\bar{n}, \\
\theta(1-\theta)-\frac{\phi n}{\Omega l(c)}, & n \geqslant \bar{n},
\end{array}\right. \\
& \bar{n}=\Psi \alpha \theta(1-\theta) \Omega l(c) \frac{1}{\rho} .
\end{aligned}
$$

This system produces the qualitative results discussed in the text. The analysis, however, is more cumbersome.

\section{A.3. Symmetric treatment of incumbents and entrants}

One might think that the results above are driven by the assumption that the R\&D expenditures of incumbents are expensible while the setup costs of entrants are not. The reason is that this assumption builds into the analysis a distortion in favor of R\&D by incumbents due to the corporate income tax since it implies a subsidy to quality growth that does not apply to variety expansion. To show that this is not the case, I now assume the R\&D expenditures of incumbents and the setup costs of entrants receive symmetric treatment.

Specifically, suppose that entry costs are subsidized at rate $\sigma t_{\Pi}$ so that in symmetric equilibrium the value of the firm is $V=\beta X\left(1-\sigma t_{\Pi}\right) .{ }^{12}$ The government's budget constraint reads

$$
G=t_{L} W L+t_{C} C+t_{\Pi}(F-\sigma R) N+t_{D} D N+t_{V} \dot{V} N-\sigma t_{\Pi} \beta X \dot{N},
$$

where the last term is the subsidy to entrants. The expression for the rate of return to equity is now

$$
r=\frac{1-t_{D}}{\beta X\left(1-\sigma t_{\Pi}\right)}\left[\left(1-t_{\Pi}\right) F-\left(1-\sigma t_{\Pi}\right) R\right]+\left(1-t_{V}\right) \hat{X}
$$

\footnotetext{
12 Observe that if $\sigma=1$, symmetric treatment of incumbents and entrants implies that the corporate income tax generates zero revenue - a fairly implausible and uninteresting case.
} 
Eqs. (15)-(19) apply unchanged. Under the assumption that tax rates are constant, the procedure followed in the text yields the steady-state locus

$$
r=\frac{1-\theta}{\beta \theta} \frac{\left(1-t_{D}\right)\left(1-t_{\Pi}\right)}{\left(1-\sigma t_{\Pi}\right)} \frac{\rho+z\left[1-\left(1-t_{V}\right) \alpha\right]}{\rho+z+\Psi \alpha \phi}+\left(1-t_{V}\right) z
$$

which is just the one in Eq. (22) divided by the factor $1-\sigma t_{\Pi}$. As one can see, therefore, as long as $\sigma<1$ there is an effect of the corporate income tax. The reason is that the effective tax rate differs across incumbents and entrants even if the nominal rate is the same. Moreover, this investment locus is everywhere above the one in Eq. (22) so that one concludes that with symmetric treatment of incumbents and entrants the steady-state growth rate is lower. This is intuitive since, with respect to the previous case, this analysis introduces in a revenue-neutral fashion a subsidy to entry. Not surprisingly, therefore, I also find that the number of firms per capita is now higher. Aside from these differences, Propositions 3 and 4 apply qualitatively unchanged.

A final observation puts this discussion in perspective. The only reason why partial expensibility of corporate $\mathrm{R} \& \mathrm{D}$ yields a distortion of the production/investment/entry choice is because there is a corporate income tax to begin with. If $t_{\Pi}=0$ partial expensibility becomes irrelevant. As discussed above, repealing the corporate income tax improves welfare if the revenue shortfall is covered by an increase of the dividend income tax. It follows that the corporate income tax should be set at zero thereby making $\sigma$ irrelevant.

\section{A.4. Positive social returns to variety}

One might think that the results obtained above depend on the assumption of zero social returns to variety. I now show that this is not so. Rewrite the production function in (1) as

$$
Y=n^{\nu} \int_{0}^{N} X_{i}^{\theta}\left(Z_{i}^{\alpha} Z^{1-\alpha} L_{i}\right)^{1-\theta} d i, \quad 0<\theta, \quad \alpha<1, \quad v>0 .
$$

Proceeding as in the body of the paper, this expression yields

$$
y=n^{\eta} \Omega l Z, \quad \eta=\frac{v}{1-\theta}
$$

so that output per capita depends positively on the number of firms per capita. ${ }^{13}$ These social increasing returns to variety are external to all agents so that their behavior does not change with respect to the characterization above. The only important difference is that the instantaneous reservation interest rate of savers now is

$$
r=\rho+z+\eta \hat{n},
$$

where the last term captures the contribution of product variety growth to total factor productivity growth. The presence of this term complicates the algebra without altering the basic results.

\footnotetext{
${ }^{13}$ See Aghion and Howitt [1] (pp. 407 and 408, in particular footnote 6) for arguments that justify introducing social returns to variety in this fashion. An alternative formulation that yields the same conclusion but is somewhat more complicated to analyze is$$
Y=N^{v}\left[\frac{1}{N} \int_{0}^{N}\left(X_{i}^{\theta}\left(Z_{i}^{\alpha} Z^{1-\alpha} L_{i}\right)^{1-\theta}\right)^{\frac{\varepsilon-1}{\varepsilon}} d i\right]^{\frac{\varepsilon}{\varepsilon-1}}, \quad 0<\theta, \quad \alpha<1, \quad v>0, \quad \varepsilon>1
$$ 
Eqs. (17) and (18) modified appropriately now yield (for simplicity I focus only on equilibria with positive $z$ )

$$
\pi=\left[\theta(1-\theta)-\frac{n^{1-\eta} \phi}{\Omega l}\right](1-\Psi \alpha)+\frac{n^{1-\eta}}{\Omega l}(\rho+\eta \hat{n}),
$$

while Eq. (20) remains unchanged. As one can see, these expressions yield a differential equation where the term $\hat{n}$ enters non-linearly. This complicates the analysis of global dynamics considerably. The local analysis, however, yields qualitative results similar to those discussed in Section 3 . To see this, consider that in steady state $\hat{n}=0$ so that the equations characterizing equilibrium of the asset market remain the same. The only difference is that now the steady-state number of firms is

$$
n^{*}=\left[\theta(1-\theta) \frac{\Psi \alpha \Omega l^{*}}{z^{*}+\rho+\Psi \alpha \phi}\right]^{\frac{1}{1-\eta}} .
$$

It is important to notice that the values $l^{*}$ and $z^{*}$ that enter this expression are exactly those that apply in the case $\eta=0$ (i.e., $v=0$ ). Thus, social increasing returns to variety simply deliver a higher number of firms per capita without changing any other feature of the steady state. Linearization around the steady state then allows me to show that the local behavior of the dynamical system is similar to that characterized in Section 3.

Things are simpler if one wants to replicate the analysis of Section 4. The reason is that the equation characterizing the return to equity is (25), instead of (20), where $T$ is a constant. Substituting the expression above for the profit ratio into (25) yields

$$
\hat{n}=\frac{\theta(1-\theta)[1-\alpha \Psi]-\frac{(\phi-\rho) n^{1-\eta}}{\Omega l^{*}}-\beta \theta^{2} \rho-T}{\beta \theta^{2}-\frac{\eta n^{1-\eta}}{\Omega l^{*}}} .
$$

As long as $\eta<1$, this differential equation has the same properties as the one analyzed above and converges to the steady state

$$
n^{*}=\left[\frac{\Omega l^{*}}{\phi-\rho}\left[\theta(1-\theta)[1-\alpha \Psi]-\beta \theta^{2} \rho-T\right]\right]^{\frac{1}{1-\eta}} .
$$

The restriction $\eta<1$ implies that positive social returns to variety do not overturn the market share effect. This ensures that the basic forces at work in the model, and therefore the characterization of the equilibrium dynamics of the decentralized market, remain qualitatively unchanged. Notice that $\eta<1$ implies $v<1-\theta$, that is, the degree of increasing returns to variety is less than the labor share. This is quite plausible. Moreover, the only reason why I need to restrict increasing returns to variety is because for analytical convenience I posited fixed operating costs in terms of the final good. If I posited fixed operating costs in units of labor, like in Peretto and Connolly [17], perpetual variety expansion would be impossible regardless of the degree of increasing return to variety. The analysis, however, would be substantially more complicated because I could not work with a constant labor share of GDP.

To check that the welfare implications remain the same as well, consider the change in welfare delivered by the policy discussed in Proposition 3 (the argument for Proposition 4 is essentially the same):

$$
\Delta U_{0}=\int_{0}^{\infty} e^{-(\rho-\lambda) t} \log \frac{u(t)}{u^{*}} d t
$$


where

$$
\log \frac{u(t)}{u^{*}}=\eta \log \frac{n(t)}{n^{*}}+\int_{0}^{t}\left[z(s)-z^{*}\right] d s .
$$

The growth/variety trade-off is now explicit since $n$ is traveling towards $n^{* *}<n^{*}$ so that $n(t)<$ $n^{*}$. Observe that by construction

$$
n(t)=n^{*} e^{\int_{0}^{t} \hat{n}(s) d s} .
$$

Therefore,

$$
\log \frac{u(t)}{u^{*}}=\eta \int_{0}^{t} \hat{n}(s) d s+\int_{0}^{t}\left[z(s)-z^{*}\right] d s .
$$

I now use the facts that $r=\rho+z+\eta \hat{n}$ and $r^{*}=\rho+z^{*}$ to rewrite this expression as

$$
\begin{aligned}
\log \frac{u(t)}{u^{*}} & =\eta \int_{0}^{t} \hat{n}(s) d s+\int_{0}^{t}\left[r(s)-\rho-\eta \hat{n}(s)-r^{*}+\rho\right] d s \\
& =\int_{0}^{t}\left[r(s)-r^{*}\right] d s
\end{aligned}
$$

where

$$
\begin{aligned}
r(s)-r^{*} & =\alpha \theta(1-\theta) \frac{\Omega l^{*}}{n(s)^{1-\eta}}-\Psi \alpha \theta(1-\theta) \frac{\Omega l^{*}}{n^{* 1-\eta}} \\
& =\alpha \theta(1-\theta) \Omega l^{*}\left[\frac{1}{n(s)^{1-\eta}}-\frac{\Psi}{n^{*^{1-\eta}}}\right]>0
\end{aligned}
$$

since $n(s)<n^{*}$ and $\Psi<1$. It is then clear that the policy delivers an increase in welfare because it raises the return to innovation, exactly as in the case discussed above of $\eta=0$.

\section{References}

[1] P. Aghion, P. Howitt, Endogenous Growth Theory, MIT University Press, Cambridge, MA, 1998.

[2] P. Aghion, P. Howitt, Growth with quality-improving innovations: an integrated framework, in: P. Aghion, S. Durlauf (Eds.), Handbook of Economic Growth, North-Holland, Amsterdam, 2005.

[3] A.J. Auerbach, Taxation and Corporate Financial Policy, in: A.J. Auerbach, M. Feldstein (Eds.), Handbook of Public Economics, Vol. 3, North-Holland, Amsterdam, 2002.

[4] D. Backus, P. Kehoe, T. Kehoe, In search of scale effects in trade and growth, J. Econ. Theory (58) (1992) 377-409.

[5] E. Dinopoulos, P. Thompson, Schumpeterian growth without scale effects, J. Econ. Growth 3 (1998) 313-335.

[6] E. Dinopoulos, P. Thompson, Scale effects in Schumpeterian models of economic growth, J. Evolutionary Econ. 9 (1999) $157-187$.

[7] K.A. Hasset, R.G. Hubbard, Tax policy and business investment, in: A.J. Auerbach, M. Feldstein (Eds.), Handbook of Public Economics, Vol. 3, North-Holland, Amsterdam, 2002.

[8] P. Howitt, Steady endogenous growth with population and R\&D inputs growing, J. Polit. Econ. 107 (1999) $715-730$.

[9] C.I. Jones, Time series tests of endogenous growth models, Quart. J. Econ. CX (1995) 495-525.

[10] C.I. Jones, R\&D-based models of endogenous growth, J. Polit. Eco. 103 (1995) 759-784.

[11] C.I. Jones, Growth: Wwith or without scale effects?, AEA Papers and Proceedings 89 (1999) 139-144.

[12] K. Judd, The optimal tax rate for capital income is negative, Hoover Institution, manuscript, 2003.

[13] C. Laincz, P.F. Peretto, Scale effects in endogenous growth theory: an error of aggregation, not specification, J. Econ. Growth 11 (2006) 263-288.

[14] P.F. Peretto, Technological change and population growth, J. Econ. Growth 3 (1998) 283-311. 
[15] P.F. Peretto, Cost reduction, entry, and the interdependence of market structure and economic growth, J. Monet. Econ. 43 (1999) 173-195.

[16] P.F. Peretto, Fiscal policy and long-run growth in R\&D-based models with endogenous market structure, J. Econ. Growth 8 (2003) 325-347.

[17] P.F. Peretto, M. Connolly, The Manhattan metaphor, Duke University, manuscript, 2004.

[18] P.F. Peretto, S. Smulders, Technological distance, growth, and scale effects, Econ. J. 112 (2002) 603-624.

[19] S. Turnovsky, Methods of Macroeconomics Dynamics, MIT University Press, Cambridge, MA, 1995.

[20] A. Young, Growth without scale effects, J. Polit. Econ. 106 (1998) 41-63.

[21] J. Zeng, J. Zhang, Long-run effects of taxation in a non-scale growth model with innovation, Econ. Lett. 75 (2002) 391-403. 